\title{
THE BEHAVIOUR OF REINFORCED BLOCKWORK WALLS IN AXIAL TENSION
}

\author{
Laurent M. Shirima and Horst. G. Schäfer ${ }^{1}$ \\ Department of Civil Engineering, University of Dar es Salaam, \\ P.O. Box 35131, Dar es salaam, Tanzania \\ ${ }^{1}$ Professor of Reinforced Concrete Structures, \\ University of Dortmund, Germany
}

\begin{abstract}
:
Reinforced blockwork with horizontally laid reinforcing bars is used for walls in liquid retaining structures in developing countries. This is the case where, the level of technology in terms of skills and equipment is not in a position to allow succesful construction of reinforced concrete walls. Blockwork walls are very sensitive to cracking which cannot be prevented by reinforcement. The major problem for designers is the behaviour of such walls in tension caused by hydrostatic pressure of the stored liquid. This paper reports results of a research work to study the behaviour of reinforced blockwork walls in tension. It was observed that cracking begins at the cross joints and continues vertically through the blocks or propagates into the horizontal joints. Even after severe cracking has taken place, tension stiffening is still offered by mortar and blocks and can be taken into consideration in the calculations of deformations and crack widths. Equations for the calculation of average gross strain are derived from the test results and numerical examples are presented.
\end{abstract}

\section{Introduction}

The behaviour of reinforced blockwork in tension is more complex than that of reinforced concrete. Even where the respective strengths of blocks and mortar are as high as that of concrete, the tensile strength of blockwork may still be lower due to the discontinuities introduced by mortar joints ${ }^{[1]}$.

In order to perform structural design of reinforced blockwork wall of a cylindrical water tank, it is obviously necessary to have the knowledge of its behaviour in tension. Tensile stresses in cylindrical walls arise as a result of hydrostatic pressure of the stored water, or by drying shrinkage. Such stresses are responsible for the deformation and cracking of the walls

\section{Research significance}

Experimental and theoretical investigations reported herein were conducted over a period of three years at the University of Dortmund, for the purpose of determining the

Faculty of Engineering,University of Dar es salaam, P.O. Box 35131, Dar es salaam, Tanzania

E-mail: Uhandisi@hotmail.com deformation and cracking behaviour of reinforced blockwork walls subjected to axial tension. The aim of the investigation was to determine the major influencing parameters, for the derivation of formulae for deformation and crack width calculations.

Through tensile tests, the formation and development of cracks, mean deformation, crack width and crack spacing were observed and measured on reinforced blockwork specimens. The results were analysed and theoretical models tested. With the help of the model, design charts or tables can be produced. This paper reports only about the deformations of specimens subjected to axial tension.

\section{Experimental Program}

A total of 18 wall specimens with the dimensions shown in Fig. 1 were manufactured by using concrete blocks, mortar and reinforcing bars of strength grade 500 (BSt 500). The specimens were designed to allow sufficient steel stress range for the study of post cracking behaviour. 


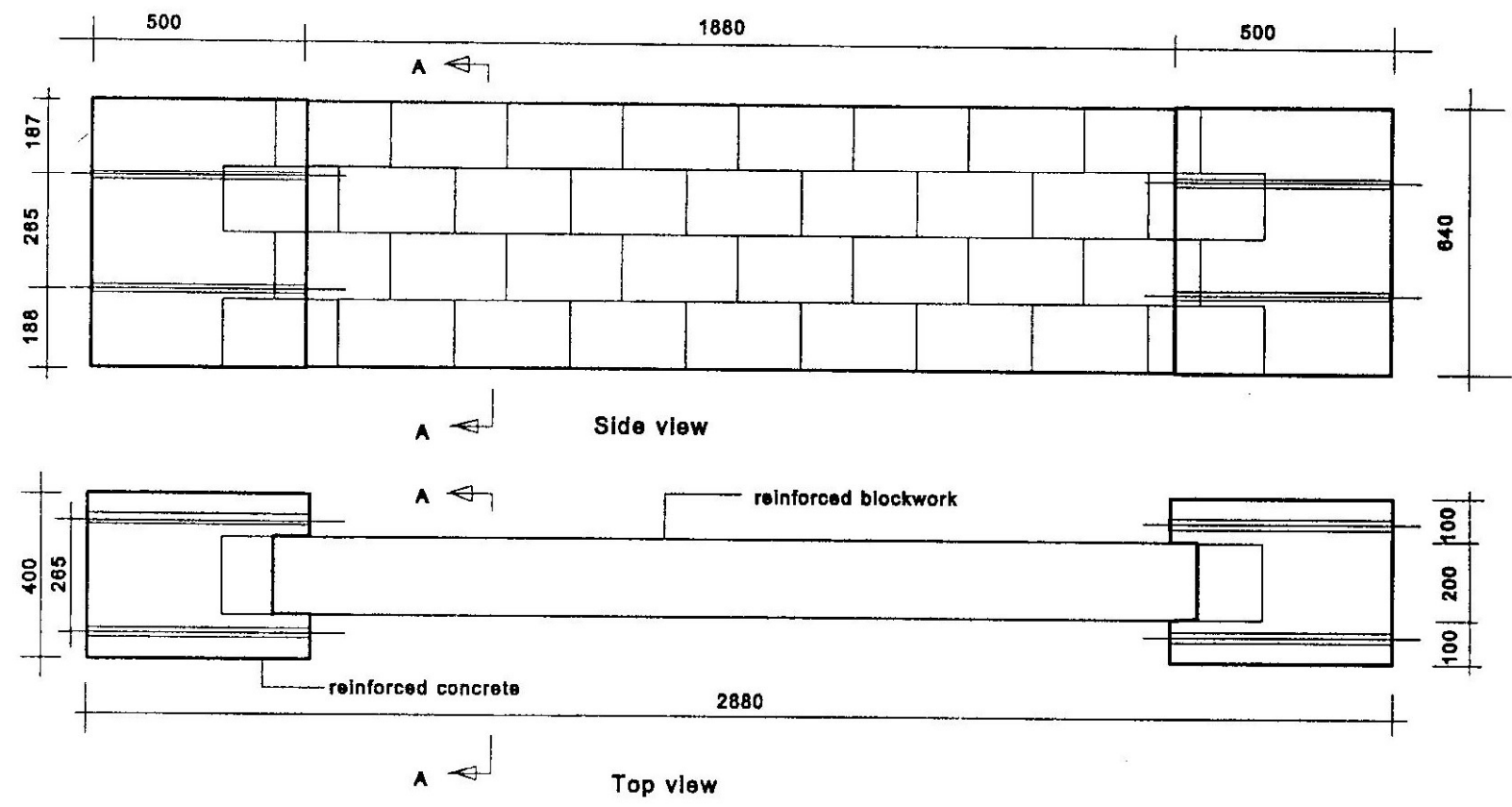

(a) Specimens WD 1 to WD 17

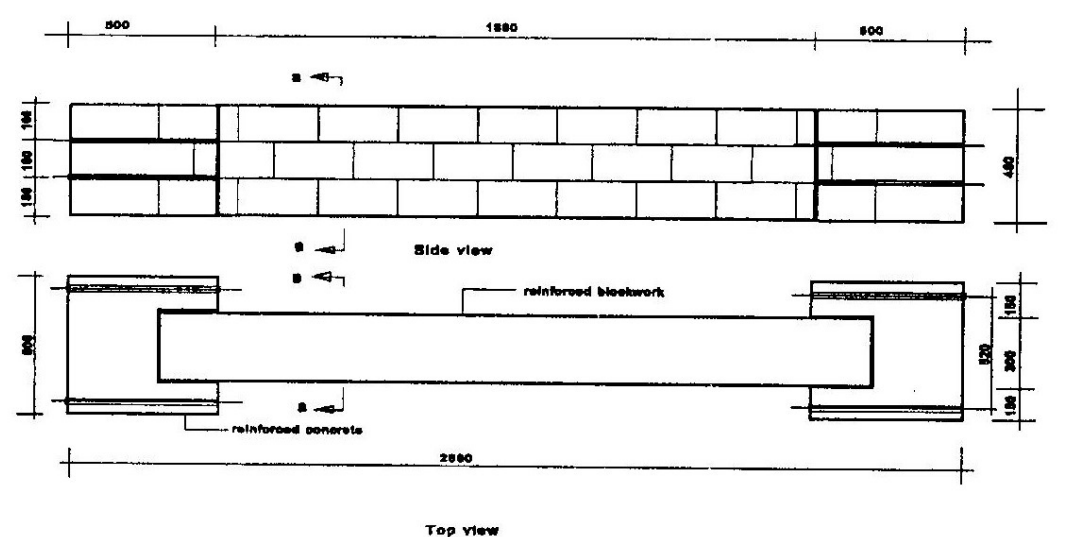

(b) Specimens WD 18 to WD 21
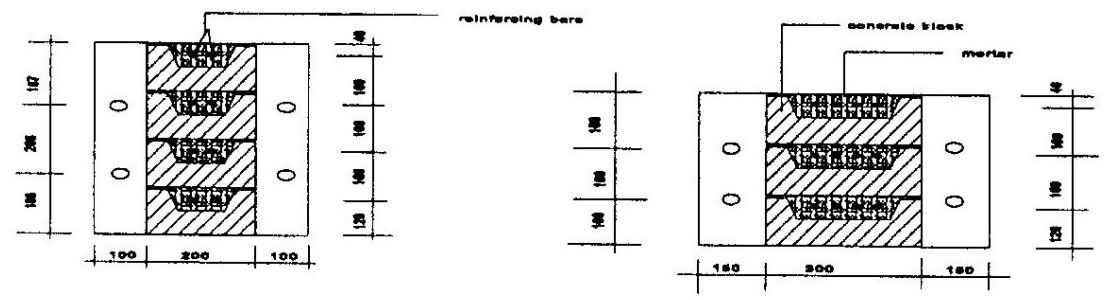

onotion a-a

Fig. 1. Specimens for axial tensile tests on reinforced blockwork

Three types of blocks were produced, namely BL1, BL2 and BL3. In order to facilitate bond between mortar and blocks, castellated formwork was used for the production of blocks types BL1 and BL3. Blocks type BL2 had relatively plain surface. The blocks were 
grooved to allow placing of reinforcement and adequate embedment in mortar.

Blocks for the preparation of wall specimens were produced at the Institute of Structural Engineering of the University of Dortmund by using Ordinary Portland cement PZ 35, sand $(0-2 \mathrm{~mm})$,aggregates $(4-8 \mathrm{~mm})$ and contained neither admixtures nor additives.

All reinforced blockwork wall specimens were produced by using a ready-mixed mortar (SAKRET), prepared under controlled factory conditions and which requires the addition of water only, as specified by the manufacturer. The SAKRET mortar is highly workable due to air entraining agents it contains and is in many respects in compliance with the requirements of DIN $1053^{[2]}$.

The reason for choosing this type of mortar was to accelerate the production of the blockwork wall specimens. Control sample strength tests on mortar produced by mixing cement and sand in a proportion 1:4 showed that the mechanical properties of SAKRET mortar did not differ significantly from the one produced locally in the laboratory.

The yield stresses of reinforcing bars available in some developing countries, e.g. Tanzania, are $250 \mathrm{~N} / \mathrm{mm}^{2}$ for mild steel (plain bars) and $410 \mathrm{~N} / \mathrm{mm}^{2}$ for deformed bars. In comparison, the type of steel available in Germany has a yield stress of at least $500 \mathrm{~N} / \mathrm{mm}^{2}$ both for plain and deformed bars (BSt $500 \mathrm{~S}$ ). Since limitation of crack widths is the primary concern, steel strains are inevitably limited to magnitudes which make it possible to assume that the steel stresses will rarely exceed 250 $\mathrm{N} / \mathrm{mm}^{2}$. As far as the design of water retaining structures is concerned, crack widths are supposed to be less than $0.20 \mathrm{~mm}$. Therefore, the use of BSt $500 \mathrm{~S}$ for our tests is not expected to affect the aim of this work.

The advantage of using BSt $500 \mathrm{~S}$, is the possibility of studying the post-cracking behaviour and tension stiffening effects of blocks between cracks, due to the availability of adequate stress range between first cracking and yield stresses.

\section{Types of specimens}

The specimens were produced on the basis of the test variables. The experimental program comprised 5 variables:

\begin{tabular}{|c|c|}
\hline 0 & reinforcement ratio $\rho\left(\mathrm{A}_{\mathrm{s}} / \mathrm{bh}\right)$, \\
\hline 0 & bar size $d_{s}$ \\
\hline & $\begin{array}{l}\text { type of reinforcement (plain or } \\
\text { deformed), }\end{array}$ \\
\hline & $\begin{array}{l}\text { type of blocks (plain or deformed } \\
\text { surface) and }\end{array}$ \\
\hline & wall width $b$. \\
\hline
\end{tabular}

One of the wall specimens was made of reinforced concrete for comparison purpose. The type of specimens and the respective test parameters are presented in Table 1.

\section{Preparation of wall specimens}

All specimens were prepared on structural steel supports in order to facilitate their transportation to the testing frame. A doublelayer foil was placed between the steel support and the wall to provide a sliding joint.

Blockwork wall specimens were produced by using the normal procedure of laying reinforced blockwork. A course of blocks was layed by filling the head joints with mortar and leaving a continuous groove. Reinforcing bars were fixed in horizontal positions by using spacer elements situated at a distance of $300-400 \mathrm{~mm}$, in order to prevent the sagging of the bars. Recommendations for minimum bar spacing and cover to reinforcement according to DIN 1053:Part 3 were followed.

Fresh mortar was filled into the grooves carefully, to ensure that all bars are fully imbedded in mortar. Compaction was done by using a trowel and upon pressing new blocks 
Table 1 Types of specimens and their main parameters

\begin{tabular}{|c|c|c|c|c|}
\hline Specimen & $\mathrm{B} / \mathrm{h}[\mathrm{mm}]$ & Type of block & Bar size $[\mathrm{mm}]$ & $\mathrm{A}_{\mathrm{s}} / \mathrm{bh}[\%]$ \\
\hline WD 1 & $210 / 640^{1)}$ & BL1 & 8 deformed & 0.45 \\
\hline WD 2 & $210 / 640^{1)}$ & BL1 & 12 deformed & 0.67 \\
\hline WD 3 & $200 / 640$ & BL1 & 8 plain & 0.47 \\
\hline WD 4 & $200 / 640$ & BL1 & 12 plain & 0.69 \\
\hline WD 5 & $200 / 640$ & $\overline{B L 1}$ & 10 deformed & 0.50 \\
\hline WD 6 & $200 / 640$ & $\overline{B L 1}$ & 10 plain & 0.48 \\
\hline WD 7 & $200 / 640$ & BL1 & 10 deformed & 0.75 \\
\hline WD 8 & $200 / 640$ & BL1 & 10 plain & 0.72 \\
\hline WD 9 & $200 / 640$ & $\mathrm{BL1}$ & 12 plain & 1.03 \\
\hline WD 10 & $200 / 640$ & BL1 & 12 deformed & 1.07 \\
\hline WD 11 & $200 / 640$ & BL2 & 12 deformed & 1.07 \\
\hline WD 12 & $200 / 640$ & BL2 & 12 plain & 1.03 \\
\hline WD 13 & $200 / 640$ & $--^{2)}$ & 10 deformed & 0.75 \\
\hline WD $14^{3)}$ & $200 / 640$ & BL1 & 12 plain & 1.03 \\
\hline WD $15^{3)}$ & $200 / 640$ & BL1 & 12 plain & 1.03 \\
\hline WD $16^{3)}$ & $200 / 640$ & BL1 & 12 plain & 1.03 \\
\hline WD 17 & $200 / 640$ & BL1 & 10 plain & 0.48 \\
\hline WD 18 & $300 / 480$ & BL3 & 10 plain & 0.80 \\
\hline WD 19 & $300 / 480$ & BL3 & 10 deformed & 0.85 \\
\hline WD 20 & $300 / 480$ & BL3 & 12 plain & 0.91 \\
\hline WD 21 & $300 / 480$ & BL3 & 12 deformed & 0.98 \\
\hline
\end{tabular}

ii)includes $5 \mathrm{~mm}$ plastering on both sides, ${ }^{2)}$ reinforced concrete specimen, ${ }^{3)}$ specimens for water flow tests.

on top, excess mortar oozed out and could be scraped until the surfaces at the joints were flush with the surface of the blockwork. The type of wall bond used for all specimens was the stretcher bond, by which the cross joints are staggered by $50 \%$ of the length of the blocks.

Two cages of reinforcing bars were fixed at the ends of each wall after the blockwork part was complete. Before casting the ends with concrete, 4 PVC tubes were fixed in each cage to leave holes for fixing threaded rods during test. Casting of the load transmission blocks was done in one operation by using a concrete mix corresponding to a strength grade 35 . Curing of the specimens was carried out for 7 days by wet sacking.

The reinforced concrete specimen WD 13 was produced by using the concrete mix design of the blocks. Its longitudinal bars were held in position with the help of stirrups and other bars. The dimensions and longitudinal reinforcement ratio of specimen WD 13 were equal to those of reinforced blockwork specimen WD 7.

\section{Test setup}

The measuring points were planned in view of the purpose at the time the walls were about to be tested. The average gross strain was measured by using 4 inductive displacement 
transducers ( 2 on each side of the specimen), with a gauge length of $1370 \mathrm{~mm}$. The measuring points were designated MS1 to MS4. These measurements were conducted on all 18 tensile test specimens. The average deformation measured from the 4 transducers was divided by the gauge length to obtain the average strain $\varepsilon_{\mathrm{m}}$.

\section{Test procedure}

All tests were conducted in a rigid testing frame. By using screw-threaded rods one end of the specimen was fixed to the testing frame while the other end was connected to an actuator fixed to the opposite end of the frame.

The loading of the specimens was performed at displacement control of $5 \mu \mathrm{m} / \mathrm{s}$ up to a load corresponding to $80 \%$ of the reinforcement's yield stress. They were then unloaded and subjected to repeated loadings between the first cracking load and the maximum load reached earlier at the frequency of $0.1 \mathrm{~Hz}$. Finally, the specimen was unloaded before reloading it again until either the failure load or the maximum capacity of the actuator was reached. Both initial and final loadings comprised 5 to 8 steps in which crack patterns were marked and measurements of crack widths were carried out.

\section{Test results}

\section{Crack strength of reinforced blockwork in tension}

Calculations of crack widths and tension stiffening in reinforced blockwork requires the knowledge of its cracking stress. Cracking stress, for the purpose of this paper, is the equivalent steel stress that corresponds to the appearance of first visible cracks at the surface of the specimen. They are mainly vertical cracks at the head joints. It is possible that some cracks may be overseen because of their too small widths. However, since data for the deformation of the specimens were continuously recorded in a computer, the initial cracking force could be retraced in the load deformation diagrams, whereby the transition from uncracked to cracked state is visible in the form of a kink, showing an obvious reduction of member rigidity.

Initial cracking loads $N_{1}$, tensile strengths of the walls upon cracking $f_{t}$, corresponding steel stresses, i.e. cracking stress $\sigma_{s 1}$ and the average wall strains for the tested 18 specimens are presented in Table 2. Tensile stress values $f_{t}$ were determined by dividing $\mathrm{N}_{1}$ by the cross-sectional area of blockwork while $\sigma_{\mathrm{s} 1}$ values were determined as follows:

$$
\sigma_{s l}=N_{1} / A_{s} \approx f_{t} / \rho
$$

According to DIN 1053:Part 2, the final shrinkage strain of concrete blockwork for planning purpose is $0.2 \mathrm{~mm} / \mathrm{m}$, which is larger than the cracking strains of the tested specimens as shown above. This confirms that reinforcement alone cannot prevent the formation of shrinkage cracks, hence other measures are necessary.

\section{Estimation of tensile strength of blockwork in axial tension}

The tensile strength of blockwork $f_{t}$ can be estimated from the compressive strength of blocks $f_{c b}$ and of mortar $f_{c m}$, by assuming that splitting of blocks occurs before the failure of horizontal joints. In this case, the tensile strength of mortar $f_{t m}$ and that of concrete blocks $f_{t b}$ are important inputs and can be determined by the equations:

$$
f_{b}=0.2 \sqrt[3]{f_{c b}^{2}} ; \quad f_{t m}=0.1 \sqrt[3]{f_{c m}^{2}}
$$

If one denotes the ratio of mortar area over the cross-section of the member by $\alpha_{\mathrm{m}}$ then the tensile strength of blockwork can be determined as follows: 
Table 2: First cracking loads, stresses and corresponding mean wall strains

\begin{tabular}{|c|c|c|c|c|}
\hline Specimen & $\mathrm{N}_{1}[\mathrm{kN}]$ & $\mathrm{f}_{t}\left[\mathrm{~N} / \mathrm{mm}^{2}\right]$ & $\sigma_{\mathrm{J}}\left[\mathrm{N} / \mathrm{mm}^{2}\right]$ & $\varepsilon_{\text {, }}[\mathrm{mm} / \mathrm{m}]$ \\
\hline WD 1 & 114 & 0.88 & 183.9 & 0.15 \\
\hline WD 2 & 106 & 0.84 & 116.4 & 0.08 \\
\hline WD 3 & 103 & 0.80 & 170.0 & 0.16 \\
\hline WD 4 & 107 & 0.84 & 123.0 & 0.09 \\
\hline WD 5 & 93 & 0.73 & 145.5 & 0.06 \\
\hline WD 6 & 107 & 0.83 & 174.0 & 0.09 \\
\hline WD 7 & 104 & 0.81 & 107.7 & 0.10 \\
\hline WD 8 & 112 & 0.88 & 121.4 & 0.10 \\
\hline WD 9 & 133 & 1.03 & 101.4 & 0.19 \\
\hline WD 10 & 133 & 0.86 & 97.2 & 0.16 \\
\hline WD 11 & 94 & 0.61 & 69.1 & 0.06 \\
\hline WD 12 & 88 & 0.68 & 66.8 & 0.03 \\
\hline WD 13 & 132 & 0.89 & 136.8 & 0.12 \\
\hline WD 14* & & & & - \\
\hline WD 15* & & & & - \\
\hline WD 16* & & & & - \\
\hline WD 17 & 65 & 0.51 & 106.2 & 0.11 \\
\hline WD 18 & 108 & 0.75 & 93.9 & 0.05 \\
\hline WD 19 & 129 & 0.90 & 105.9 & 0.08 \\
\hline WD 20 & 116 & 0.81 & 87.9 & 0.08 \\
\hline WD 21 & 130 & 0.90 & 92.8 & 0.08 \\
\hline
\end{tabular}

* were specimens for water flow tests

$$
f_{t}=\alpha_{m} f_{t m}+\left(1-\alpha_{m}\right) \frac{f_{t b}}{2}
$$

Equations (2) and (3) were applied to 28 days compressive strength test results of block concrete and mortar for comparison with the tensile strength results shown in Table 2 . The

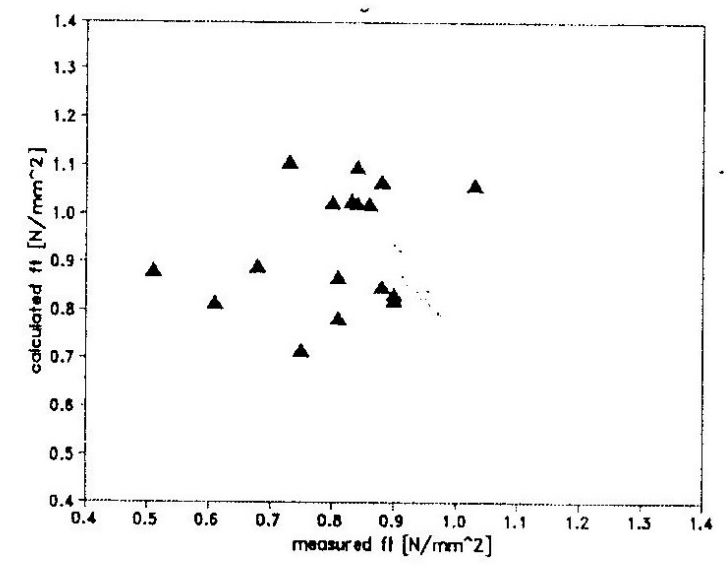

Fig. 2 Comparison between calculated and measured tensile strength of blockwork $f_{t}$

Faculty of Engineering,Universlty of Dar es salaam, P.O. Box 35131, Dar es salaam, Tanzania results were found to be in good agreement with the tests data as shown in Fig. 2.

\section{Crack formation and final crack patterns}

Initial cracking in all reinforced blockwork wall specimens began at the vertical mortar joints. For the majority of specimens, more vertical cracks occurred as the load increased; they propagated vertically into the adjacent blocks. Otherwise, crack formation followed the pattern of the head and bed joints.

There are three basic patterns of cracks which were observed during the tests (Fig. 3):

Case 1: Cracks began at the vertical joints and extended into the adjacent blocks, followed by failure of the bed joints. This was the case for the majority of specimens comprising blocks type BL1 or BL3. 

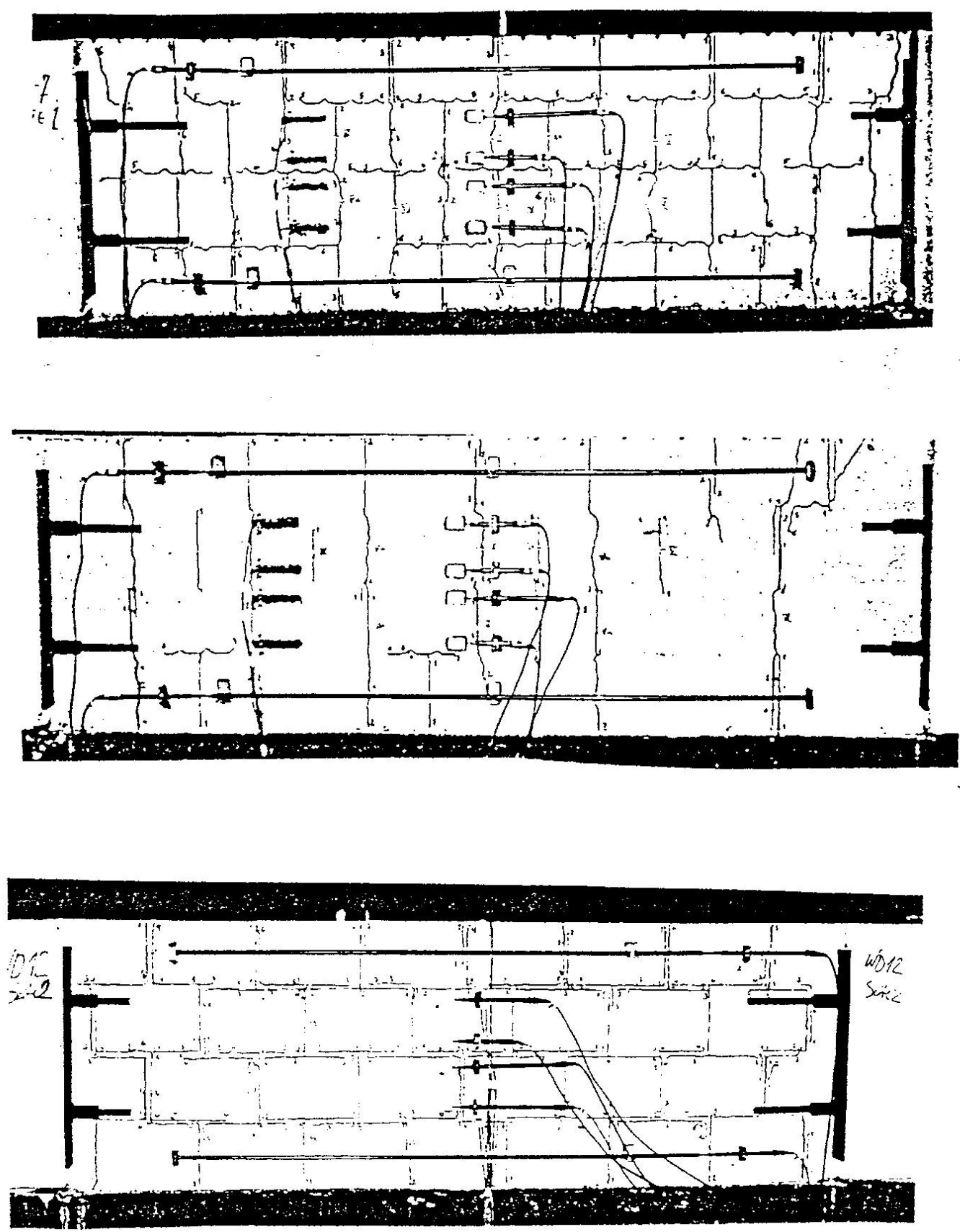

Fig. 3. Final crack patterns for specimens (a) Majority of specimens (b) Specimen WD ( (c) Specimen WD 12 
Case 2: Cracks occurred at the vertical joints and extended across the entire ection or partly into the adjacent blocks. Examples of such type of crack configuration appeared on specimens WD 6 and WD 8, for which blocks type BL1 were used for the walls.

Case 3: Cracks which appeared at the vertical joints did not propagate into the adjacent blocks. The final configuration was the same as the pattern of joints. This occurred when relatively smooth blocks type BL2 wereused for specimens WD 11 and WD 12.

It is perhaps necessary to make a remark at this point, that in practice, cylindrical walls of a water storage tank are under the action of vertical compression, especially near the bottom, where high tensile ring forces are expected. Assuming that blocks will have adequate surface roughness, it is unlikely that cracks will propagate into the bedding joints. In comparison, the reinforced blockwork wall specimens were not high enough to accurately simulate the conditions encountered in practice. If adequate vertical compression had been available, the crack pattern would have mainly comprised vertical cracks and rarely horizontal ones.

Observations on the final crack configuration of the majority of specimens indicated that the topmost course cracked at the head joints only, leaving the blocks uncracked, whereas in the courses below, cracks occurred at the blocks as well. One may conclude that the specimens represent the most unfavourable case to be met in practice. Furthermore, the pattern of cracks on the mortar run in the topmost course of the specimens was observed to be different from the one that appeared on sides of the same course. This suggests that absence of vertical compression may cause mortar cracking that is independent of the block patterns.

The crack configuration stabilised to its final form even before reaching the maximum service load ( $80 \%$ of yield stress). The application of repeated loading did not bring about new cracks on the surface of the specimens. Some cracks did not close completely after the specimen was unloaded possibly due to broken particles displaced on the fractured surfaces. The minimum crack spacing (rough blocks) was about $12 \mathrm{~cm}$, i.e. half block length while the maximum spacing (smooth blocks) was around $25 \mathrm{~cm}$.

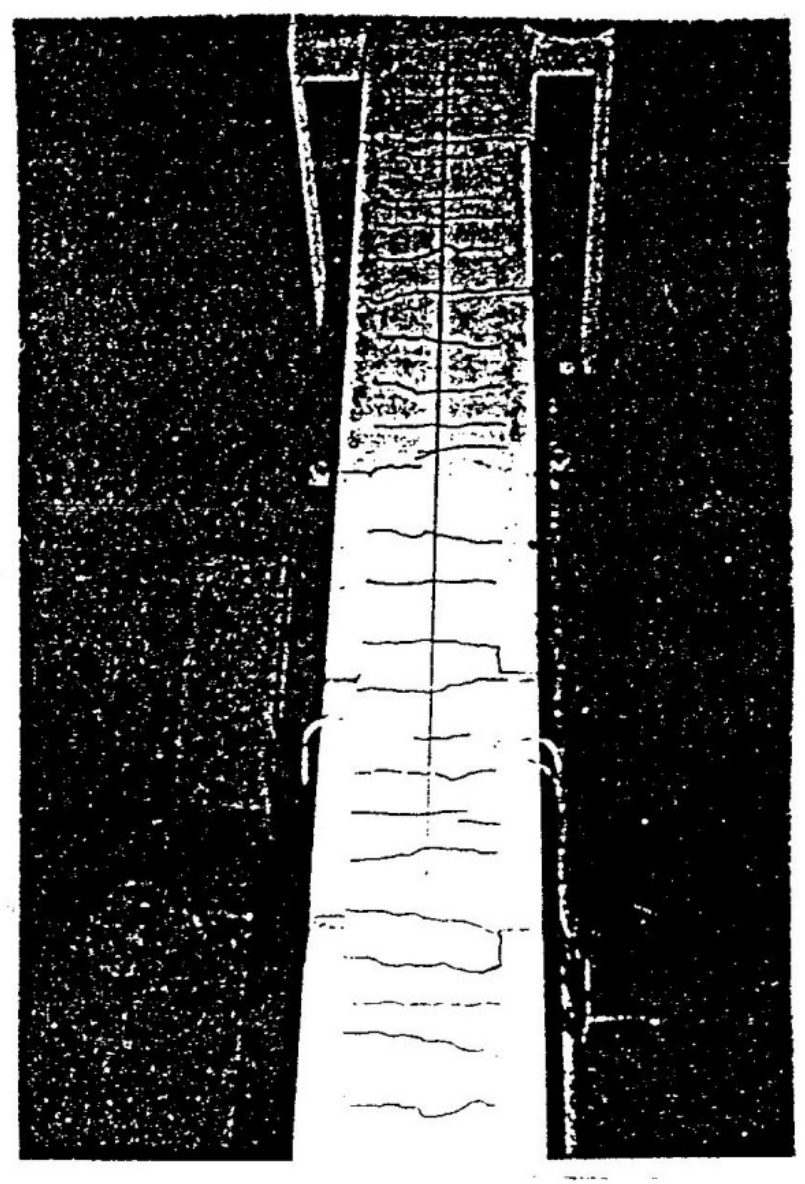

Fig. 4: Crack pattern of mortar in the absence of vertical compression

Average gross strain and tension stiffening The mean axial deformation of each reinforced blockwork in tension was determined from the average of 4 measurements from transducers. The gauge length of measurement for the axial elongation was $1370 \mathrm{~mm}$, from which the mean strain was calculated by dividing the mean elongation by $1370 \mathrm{~mm}$. Load-deformation diagrams were produced, an example of which is shown in Fig. 5. 


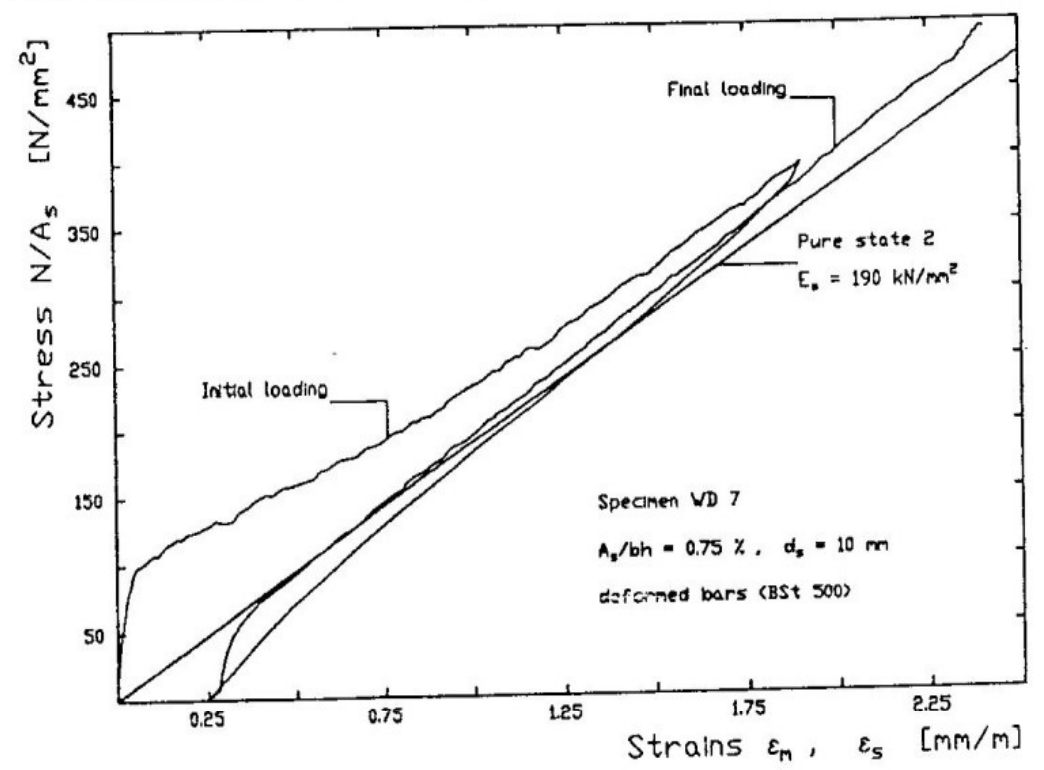

Fig. 5. Load-deformation diagram of a reinforced blockwork specimen in axial tension

Initially, the slope of the load-deformation curve is almost constantly large and represents the stiffness of the uncracked specimen. Upon cracking, the stiffness decreases with the increase in load. The reasons for the decrease in stiffness are cracking, bond failure at the mortar-reinforcement interface and shearing of bed joints between courses of blockwork. As the load increases, the average gross strain of the specimen is still smaller than that of bare steel reinforcement for a given stress, due to the contribution of mortar and blocks in bearing tension, even after severe cracking has occurred.

During the time of crack width measurements, the measured force dropped slightly, i.e. relaxation, because the elongation of the specimen was sustained. This happens because the force required to initiate a crack is larger than that required for its propagation. The relaxation disappears upon further loading.

The contribution of blockwork between cracks in bearing tension was larger for specimens with lower reinforcement ratio than was the case for elements with higher percentage of reinforcement. This applies only for initial loading and stresses not exceeding 300 $\mathrm{N} / \mathrm{mm}^{2}$. There were no clear indications to suggest any relationship between tension stiffness and the type of reinforcement used.

There were residual strains in all specimens after complete unloading had taken place, that range between 0.2 and $0.5 \mathrm{~mm} / \mathrm{m}$, that was independent of reinforcement ratio, type of bar, or the maximum

load reached. This means that the reinforcing bars remained with residual tensile stresses while the blockwork was under residual compression.

After 50 load repetitions were performed, final reloading was carried out. For loads less than the maximum reached during the initial loading, strains were larger, while the final loading curve tended to approach the old curve gradually as load increased. Upon reaching or exceeding the maximum load which was reached during the initial loading phase, the new curve followed the path of the "old one and shows that there is a similarity between the behaviour of reinforced blockwork and that of reinforced concrete.

Possible causes for larger strain during the final loading are: 
o formation of new internal and secondary cracks during load repetitions,

o increased slips between reinforcing bars and the embedding mortar,

o plastification of mortar struts at the lugs of deformed bars,

o failure and falling out of mortar cones adjacent to the cracks, thus leading to increased tensile strain in steel bars and/or

o irreversible deformations at the mortar joints.

In the literature survey, it was observed that there are various models (equations), that describe the stress-strain relationship of reinforced concrete in tension, by taking into consideration tension stiffening. None of those models can be directly applied to reinforced blockwork without modifications. There are two approaches by which stress-strain relationship can be formulated. One of them is based on material laws as reported by Noakowski $^{[4]}$, König and Fehling ${ }^{[5]}$ and Schie $B 1^{[6]}$. Another approach is to determine approximate mathematical expressions that fits best into the test results as applied by Mehlhorn and Gunther ${ }^{[7]}$, which shows that several models are possible.

The approach that will be applied for modelling tension stiffening effects and average gross strain of reinforced blockwork in axial tension is a combination of those mentioned mentioned above. In this case, we assume the following relationship:

$\varepsilon_{m}=\frac{\sigma_{s}}{E_{s}}\left[1-k_{s}\left(\frac{\sigma_{s l}}{\sigma_{s}}\right)^{n}\right]$

Where ks and $\mathrm{n}$ are constants to be determined from the test results. According to equation (4), the difference between average gross strain and strain in pure state 2 , denoted by $\Delta \epsilon_{\mathrm{s}}$ can be written as follows:

$$
\Delta \varepsilon_{s} / \varepsilon_{s 2}=k_{s}\left(\frac{\sigma_{s l}}{\sigma_{s}}\right)^{n}
$$

The equation becomes

$$
\log \left(\frac{\Delta \varepsilon_{s}}{\varepsilon_{s 2}}\right)=\log \left(k_{s}\right)+n\left(\frac{\sigma_{s l}}{\sigma_{s}}\right)
$$

The experimental data were tested by using a linear regression with a best-fitiuess cuefficient of at least $90 \%$ to determine $n$ and $\log \left(\mathrm{k}_{\mathrm{s}}\right)$ of the above equation. The procedure was applied both in the apparently initial $\left(\mathrm{k}_{\mathrm{s} 1}, \mathrm{n}_{\mathrm{l}}\right)$ and final crack $\left(\mathrm{k}_{\mathrm{s} 2}, \mathrm{n}_{2}\right)$ formation stages. The results of this analysis are presented in Table 3. Specimens WD 6, WD 17 and WD 21 produced values of $\mathrm{k}_{\mathrm{s}}$ and $\mathrm{n}$ that were too large and were therefore not included in determining the mean values at the bottom of the table.

Table 3: Values for tension stiffening coefficients

\begin{tabular}{||l|c|c|c|c||}
\hline Spec. & $\mathrm{K}_{s 1}$ & $\mathrm{n}_{1}$ & $\mathrm{k}_{\mathrm{s}_{2}}$ & $\mathrm{~N}_{2}$ \\
\hline WD 1 & 0.772 & 3.346 & 0.586 & 2.333 \\
\hline WD 2 & 1.100 & 2.967 & 0.779 & 2.224 \\
\hline WD 3 & 0.601 & 2.785 & 0.349 & 1.345 \\
\hline WD 4 & 0.764 & 2.739 & 0.359 & 0.948 \\
\hline WD 5 & 1.069 & 2.501 & 0.647 & 1.539 \\
\hline WD 7 & 0.881 & 2.075 & 0.443 & 1.313 \\
\hline WD 8 & 0.843 & 2.630 & 0.364 & 1.177 \\
\hline WD 9 & 0.616 & 2.154 & 0.464 & 1.617 \\
\hline WD 10 & 0.664 & 1.769 & 0.472 & 1.317 \\
\hline WD 11 & 0.970 & 1.789 & 0.418 & 0.963 \\
\hline WD 12 & 1.070 & 1.868 & 0.667 & 1.142 \\
\hline WD 18 & 1.060 & 2.411 & 0.281 & 1.656 \\
\hline WD 19 & 0.853 & 2.346 & 0.971 & 2.563 \\
\hline WD 20 & 0.905 & 2.526 & 1.090 & 2.645 \\
\hline Mean & 0.869 & 2.422 & 0.564 & 1.627 \\
\hline Std-dev & 0.171 & 0.461 & 0.243 & 0.580 \\
\hline Var-coef & 0.197 & 0.190 & 0.430 & 0.356 \\
\hline \hline
\end{tabular}

This indicates that the average gross strain for the initial crack formation is given by the equation: 
$\varepsilon_{m}=\frac{\sigma_{s}}{E_{s}}\left[1-0.87\left(\sigma_{s l} / \sigma_{s}\right)^{2.4}\right]$

while for final crack formation,

$$
\varepsilon_{m}=\frac{\sigma_{s}}{E_{s}}\left[1-0.55\left(\frac{\sigma_{s l}}{\sigma_{s}}\right)^{1.6}\right]
$$

is considered more representative.

\section{Application}

mean crack width due to load. For stabilized crack configuration in our tests, for which mean crack spacing $\mathrm{s}_{\mathrm{m}}$ was almost equal to half block lengths in case of rough blocks, and double as much in case of smooth blocks, the mean crack width $\mathrm{w}_{\mathrm{m}}$ can be calculated as follows:

Comparison between measured and calculated mean crack widths using the above equations has depicted a good agreement as can be seen in Fig. 6 below.

Equation (8) is useful for the calculation of

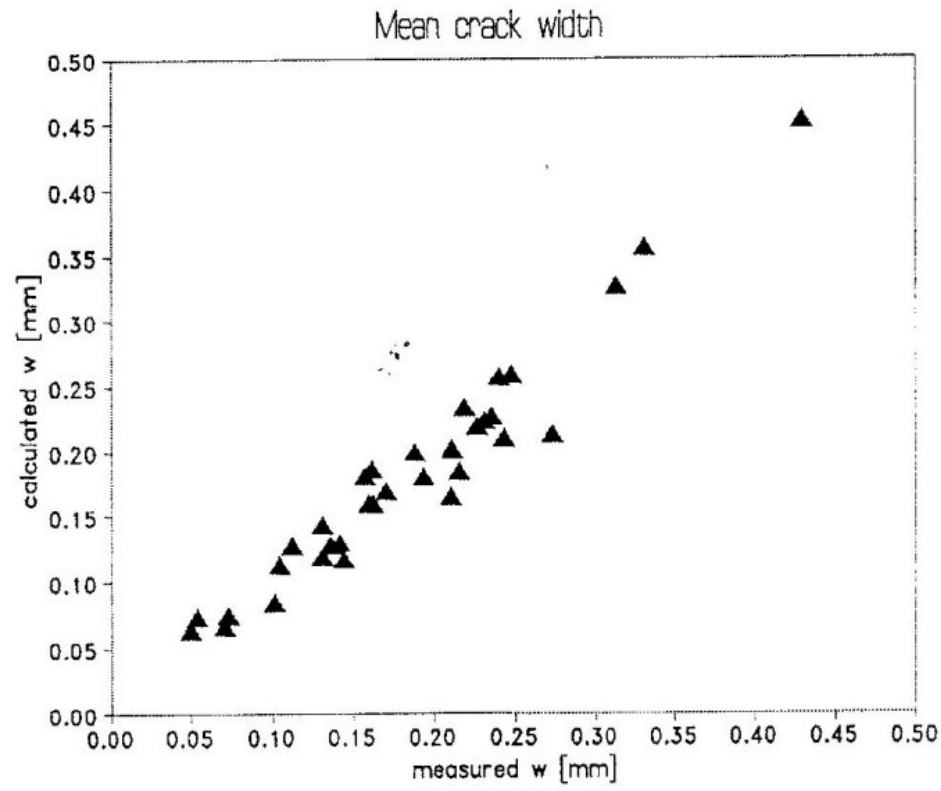

Fig. 6. Comparison between measured and calculated mean crack widths

Design charts or tables can be produced for the determination of reinforcement required to limit crack widths in serviceability limit state design. This is particularly important for water storage tanks by which smaller crack widths may reduce losses due to leakage and chances of self healing of cracks are large.

\section{Conclusions and recommendations}

In view of the results of this work some basic information about the behaviour of reinforced blockwork in axial tension could be obtained. However the results are based on tests conducted by considering the most unfavourable conditions which can rarely occur in practice. One of the conditions under which the tests were performed is the absence of adequate vertical compression force.

It is well known that the shear strength (friction) along the bedding joints depends on the vertical compression. In practice the compression force exists as a result of weight 
of the slabs, beams and courses of blocks above the level of consideration. Walls of cylindrical reinforced blockwork water tanks experience more tension at locations near the bottom. Based on this assumption it is likely that the values of blockwork tensile strength are higher in practice than the ones determined from this work. Horizontal cracks are unlikely to occur in such cases. The behaviour of reinforced blockwork in tension has demonstrated that there are some similarities with reinfurced concrete, particulariy the contribution of mortar and blocks between cracks.

Further studies on the behaviour of reinforced blockwork in tension are recommended, particularly with regard to the influence of vertical compression on the tensile strength, tension stiffening, crack widths and crack spacing.

\section{Acknowledgement}

This research work was sponsored by the German Research Association. Testing equipment and manpower for the preparation of test specimens and experimental setups was made available by the Institute of Structural Engineering of the University of Dortmund.

\section{References}

1. Al-Manaseer, A. A. and Neis, V. V. (1987) "Load Tests on Post-tensioned Masonry Wall Panels," ACI Structural Journal, 84, pp 467-472.

2. DIN 1053 (1984): "Masonry: Part 2: Design and Construction, "Beuth Verlag, Berlin

3. Senyange, K. (1987) "Design of Reinforced Blockwork Storage Tanks," M.Sc Thesis, University of Dar es Salaam

4. Noakowski, P. (1986) "Tension Stiffening Laws for the Determination of Deformations ad Constraint at Loading," Beton- . Stahlbetonbau, 84, pp. 318-325

5. Koenig, G. and Fehling, E. (1988) "Limiting the Crack Width in Reinforced Concrete Construction," Beton- u. Stahlbetonbau, 83, pp. 199-204

6. Schiessl, P. (1989) "Principles of the New Regulations for the Limitation of Crack Width," Deutscher Ausschuss f. Stahlbetonbau, 400, pp. 157-175

7. Guenther, G. and Mehlhorn, G. (1991) "Centrical Tension Tests on Reinforced Concrete Specimens for the Determination of Tension Stiffening," Beton- u. Stahlbetonbau, 86, pp. 65-67

\section{Notations}

\begin{tabular}{|c|c|c|c|}
\hline $\begin{array}{l}A_{s} \\
b\end{array}$ & $\begin{array}{l}\text { Area of steel reinforcement } \\
\text { wall thickness }\end{array}$ & $\sigma_{s 1}$ & $\begin{array}{l}\text { steel stress corresponding } \\
\text { to first crack }\end{array}$ \\
\hline$d_{s}$ & bar size (diameter) & $\sigma_{s}$ & steel stress at the cracks \\
\hline $\mathrm{E}_{\mathrm{s}}$ & modulus of elasticity of steel & $\rho$ & reinforcement ratio \\
\hline$f_{c b}$ & compressive strength of blocks & $\mathrm{s}_{\mathrm{m}}$ & crack spacing \\
\hline $\mathrm{f}_{\mathrm{cm}}$ & compressive strength of mortar & $\mathrm{w}_{\mathrm{m}}$ & crack width \\
\hline$f_{t}$ & tensile strength of blockwork & $\alpha_{\mathrm{m}}$ & mortar ratio \\
\hline $\mathrm{f}_{\mathrm{tb}}$ & tensile strength of blocks & $\Delta \varepsilon_{\mathrm{s}}$ & tension stiffening \\
\hline $\mathrm{f}_{\mathrm{tm}}$ & tensile strength of mortar & $\varepsilon_{1}$ & cracking strain \\
\hline $\mathrm{k}_{\mathrm{s}}$ & tension stiffening constant & $\varepsilon_{\mathrm{m}}$ & average blockwork strain \\
\hline $\begin{array}{l}k_{\mathrm{s} 1} \\
k_{\mathrm{s} 2}\end{array}$ & $\begin{array}{l}\text { tension stiffening constant for initial cracking phase } \\
\text { tension stiffening constant for final cracking phase }\end{array}$ & $\varepsilon_{\mathrm{s} 2}$ & $\begin{array}{l}\text { steel strain in pure state II (at } \\
\text { a crack) }\end{array}$ \\
\hline & measure of the curvature of load-deformation curve & & \\
\hline n1 & for initial crack formation & & : \\
\hline $\mathrm{n} 2$ & for final cravk formation & & \\
\hline
\end{tabular}




\title{
The Resource Leveling Problem (RLP) Mixed-Integer Programming Formulations (MIP)
}

\author{
Allen Mushi \& Micheal O'Heigeartaigh \\ Department of Mathematics
}

\begin{abstract}
Resource Leveling is a variation of the resource-constrained scheduling problem. Initially the critical path through a network of tasks (each with a given resource requirement) is determined with all activities tentatively scheduled at their latest start times. For this schedule, a profile of the total resource requirement over time is obtained (i.e. the sum of the resource requirements of the tasks overlapping at each particular time are calculated). We then level the resource peaks as much as possible, subject to the time constraints of the activities [1].

In this paper, four different Mixed Integer Programming formulations of the RLP are presented. We conclude that the time indexed formulations give $a$ better lower bound on the linear programming relaxation and hence a better starting point for the Integer Programming algorithms.
\end{abstract}

\section{Introduction}

Scheduling a project consists of determining a set of starting times for the activities of the project in such a way that the precedence constraints between them are satisfied and the total completion time is minimized. If there are no resource constraints, problems of realistic size can be solved by the critical path and network flow techniques. The activity start times developed from these techniques imply specified patterns or 'profiles' of resource usage over time. When resource availability levels are checked against the required levels of demand, the problem of resource allocation arises. It may be that demands exceeds availability levels in certain time periods or that the variation in resource profiles is considered excessive, and there is a reason to reduce excessive peaks and 'smooth' the profiles of usage.

The objective of the resource leveling process is to 'smooth' as much as possible the profiles of usage over time, within the given project duration. This is accomplished by judicious rescheduling of activities within their available slack (floating time) to give the most acceptable profile.

Faculty of Engineering, University of Dar es salaam, P. O. Box 35131, Dar Es salaam, Tanzania
This is an NP-Hard combinatorial optimization problem and thus no exact algorithm is currently known for the solution. However, RLP has major applications in manufacturing Industry[2]

\section{Application of RLP in Manufacturing Industry}

In manufacturing industry, the scheduling process involves the allocation of the available capacity or resources (equipment, labor, and space) to jobs, activities, tasks, or customers through time [3]. Important documents required in this process include the Bill of Material (BOM) and the Master Production Schedule (MPS). One of the applications of both these documents (BOM and MPS) is to develop a resource profile by the work center (or facility). This is used to determine whether the given orders can be delivered within the given time scale (Planning horizon) without exceeding the available resources. The most even profile is therefore desired so as to optimize the use of the available resources. 


\section{Model developments Assumptions}

- No preemption i.e. the processing of an activity must be completed without interruption once started.

- Integral stating times i.e. an activity can start only on integral time units.

- The resource requirement of an activity is known and constant throughout the planning horizon.

- There is an unlimited amount of resources and our task is to determine the minimum amount required to complete the project.

- There is a pre-specified planning horizon within which all activities must be scheduled without violating the given precedence constraints.

Model 1 : Start-time variables and timeindexed resource determining variables.

Let $\quad \mathrm{x}_{\mathrm{i}}=$ Start time of activity $\mathrm{i}$.

$\mathrm{r}_{\mathrm{i}}=$ Resource level corresponding to activity i. ( the amount of work units required to be performed on an activity per unit time )

$\mathrm{p}_{\mathrm{i}}=$ Processing time of activity $\mathrm{i}$.

$S_{i}=\left[x_{i}, x_{i}+p_{i}-1\right]$. A set of points covered by activity $i$ on the planning horizon, given that it starts at $\mathrm{x}_{\mathrm{i}}$.

$\mathrm{N}=\{1,2, \ldots, \mathrm{T}\}$. A set of all points on the planning horizon

$h_{t}=$ Total resource level in the resource profile at time t. (Height of the resource profile at time t) i.e. $h_{t}=\sum_{\forall i t t \in S_{i}} r_{i}$ i.e.

for all activities $i$ such that $t$ lies in the interval $\left[\mathrm{x}_{\mathrm{i}}, \mathrm{x}_{\mathrm{i}}+\mathrm{p}_{\mathrm{i}}-1\right]$.

$\mathrm{n}=$ Total number of activities

$\mathrm{T}=$ The length of the planning horizon (Project duration) $=|\mathrm{N}|$

$\mathrm{H}=\mathrm{A}$ set of all $\operatorname{arcs}(\mathrm{i}, \mathrm{j})$ in the network such that $i$ precedes $\mathrm{j}$.

Then the RLP is;

Min.( Max. $\left.\underset{\forall t \in N}{ }\left\{h_{t}\right\}\right)$

s.t. $\quad x_{j}-x_{i} \geq p_{i} \quad \forall(i, j) \in H$
$\dddot{x} \in 9_{+}{ }^{n}$
Or,

Min. w

s.t $\quad \mathrm{h}_{\mathrm{t}} \leq \mathrm{w} \quad \forall \mathrm{t} \in \mathrm{N}$ $x \in 9_{+}{ }^{n}, x_{j}-x_{i} \geq p_{i}, w \in 3_{+}, h \in 9_{+}{ }^{T} \quad \forall(i, j) \in H$

Let,

$$
y_{i t}=\left\{\begin{array}{cc}
1 \text { if } x_{i} \leq t \leq x_{i}+p_{i}-1 \\
0 & \text { Otherwise }
\end{array}\right.
$$

Then $\mathrm{h}_{\mathrm{t}}=\sum_{\mathrm{i}} \mathrm{r}_{\mathrm{i}} \mathrm{y}_{\mathrm{it}} \quad \mathrm{t}=1,2, . . \mathrm{T}$.

Condition (2) means that;

(i) $\sum_{t=x_{i}}^{x_{i}+p_{i}^{-1}} y_{i t}=p_{i} \quad i=1,2, \ldots n$

and

(ii) $y_{i t}=0 \quad \forall t \notin\left[x_{i}, \quad x_{i}+p_{i}-1\right]$, $\mathrm{i}=1,2, . ., \mathrm{n}$.

We need to define this condition without variable bounds. We change the bounds in condition (i) and sum for all values of $t$ in the planning horizon and then reinforce condition (ii).

(iii) $\sum_{t} y_{i t}=p_{i} \quad i=1,2, \ldots n$

(iv) $\mathrm{y}_{\text {it }}=0 \quad \forall \mathrm{t}>\mathrm{x}_{\mathrm{i}}+\mathrm{p}_{\mathrm{i}}-1, \quad \mathrm{i}=1,2, \ldots, \mathrm{n}$

(v) $\mathrm{y}_{\text {it }}=0 \quad \forall \mathrm{t}<\mathrm{x}_{\mathrm{i}}, \quad \mathrm{i}=1,2, \ldots, \mathrm{n}$

The following constraint reinforces (iv);

ty $y_{\text {it }} \leq \mathrm{x}_{\mathrm{i}}+\mathrm{p}_{\mathrm{i}}-1 \mathrm{i}=1,2, \ldots, \mathrm{n}$.

Noting that the symbol $\mathrm{T}$ stands for the length of the planning horizon, the following condition reinforces $(v)$;

$$
\left(x_{i}-t\right)-T\left(1-y_{i t}\right) \leq 0
$$

or $x_{i}+T y_{i t} \leq(t+T) i=1,2, . ., n \quad$ (5) Applying (3), (4) and (5) in (1) we have the following MIP formulation; Min.w.

s.t.

(i) $\sum_{i} r_{i} y_{i t} \leq w \quad t=1,2, \ldots, T$

(ii) $\sum_{t} y_{\mathrm{it}}=p_{i} \quad i=1,2, \ldots, n$

(iii) $t y_{i t} \leq x_{i}-p_{i}-1 \quad i=1,2 \ldots, n ;-t \in N$

(iv) $x_{i}+T y_{i:} \leq(t+T) \quad i=1,2, \ldots, n:-t \in N$

(v) $x_{j}+x_{i} \geq p_{i} \quad \forall(i, j) \in H$

$(v i)_{x_{i}} \leq T-p_{i} \quad i=1,2, \ldots, n$ 
(vii) $\mathrm{y} \in\{0,1\}^{\mathrm{n}_{\mathrm{x}} \mathrm{T}}, \mathrm{x} \in 9_{+}{ }^{\mathrm{n}}, \mathrm{w} \in 3$

Where $9_{+}$is the set of all nonnegative integer numbers. This formulation has $\mathrm{n}(\mathrm{T}+1)+1$ variables and $T(2 n+1)+2 n+|H|$ constraints, where $|\mathrm{H}|$ is the cardinality of $\mathrm{H}$.

\section{Example}

Example problems were generated randomly [2] and tested for all types of formulations. The problem (C3_02b) has 10 activities and a planning horizon of length 42 . The names of generated files represents the number of levels and branching factor used in the generation of the problem. Thus $\mathrm{C} 3 \_2$ represents a problem with 3 levels and a branching factor range between 0 and 2 on each node of the generated graph [2].

The SCICONIC package [4] (running on $\mathrm{VAX} / \mathrm{VMS}$ ) was used to solve the test problems. The Matrix Generator Generator (MGG) was used to generate the initial problem in MPS format using the two files MGG problem and MG Data Input, as presented in the appendix. These files were compiled, linked and run to produce an MPS matrix. The generated matrix was then solved by the SCICONIC programs called PRIMAL (for Linear Programming) and GLOBAL (for Branch and Bound [5]).

The MPS matrix generated for this model has 431 variables, 916 constraints with sparsity factor of $0.64 \%$. The LP value (Lower Bound) obtained from the Primal procedure was 13.02 . Integral solution was obtained after 2778 iterations. The highest level in the resource profile was found to be 19. The corresponding resource profile is shown in Fig. 1

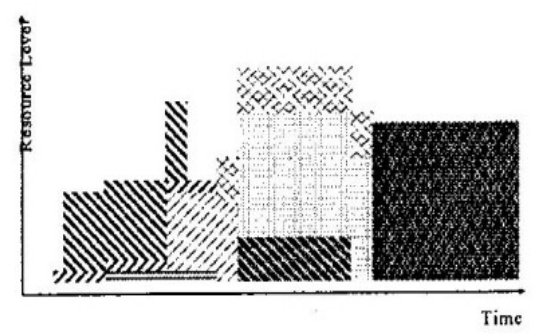

Fig. 1: Resource Profile associated with the solution of model 1

\section{Model 2 : Pure time-indexed formulation}

Time-indexed formulation uses time as indices on the variables $[6,7]$.

Let $\quad \mathrm{x}, \mathrm{r}, \mathrm{p}, \mathrm{h}, \mathrm{n}, \mathrm{S}, \mathrm{N}, \mathrm{T}, \mathrm{H}$ be as defined in the previous formulation i.e. equation (6) and the RLP;

Min. w

$$
\begin{array}{lll}
\text { s.t. } & h_{t} \leq w \quad \forall t \in N \\
& x_{j}-x_{i} \geq p_{i} \quad \forall(i, j) \in H \\
& x \in 9_{+}{ }^{n}, h \in 9_{+}{ }^{\top}, w \in 3_{+}
\end{array}
$$

Now;

Let $y_{i t}= \begin{cases}1, \text { if activity } i \text { starts at time } t \\ 0, & \text { otherwise. }\end{cases}$

Since an activity can start only once, then

$\sum_{t} y_{i t}=1 \quad \mathrm{i}=1, \ldots \mathrm{n}$

The starting time of an activity $i$ is then given by

$\mathrm{x}_{\mathrm{i}}=\sum_{t} t y_{i t} \quad \mathrm{i}=1,2, . ., \mathrm{n}$

and the precedence relations changes to

$$
\left.\sum_{t(} y_{j t}-y_{i t}\right) \geq p_{i} \quad \forall(i, j) \in H .(9)
$$

We can reinforce the resource constraint by noting that 


$$
\underset{k=t-p_{i}+1}{t} y_{i k}=1 \text { only if } t \text { lies in the }
$$

processing time interval of activity i i.e. $\mathrm{t} \in\left[\mathrm{x}_{\mathrm{i}}, \mathrm{x}_{\mathrm{i}}+\mathrm{p}_{\mathrm{i}}-1\right]$ and zero otherwise ${ }^{[8]}$

Thus $h_{t}=\sum_{i} r_{i}\left(\underset{k=t-p_{i}+1}{\sum_{i k}^{t} y_{i k}} \forall \mathrm{t} \in \mathrm{N}\right.$.

This gives the formulation:

$\min w$

$s t$.

$\sum_{t} y_{i t}=1, \quad i=1, \ldots, n$

$\sum_{t} t\left(y_{j t}-y_{i t}\right) \geq p_{i}, \quad \forall(i, j) \in H$

$\sum_{i} r_{i}\left(\sum_{k=1-p_{i}+1}^{t} y_{i k}\right) \leq w, \quad t=1, \ldots, T$

$\mathrm{y} \in\{0,1\}^{\mathrm{n}_{\mathrm{x}} \mathrm{T}}, \mathrm{w} \in 3_{+}$

This formulation has $\mathrm{nT}+1$ variables, which is less than the previous model $(\mathrm{n}(\mathrm{T}+1)+1)$. It also have $n+|H|+T$ constraints which is far less than the previous model ( $T(2 n+1)+n+|H|)$. The previous example was used to test this model, where the corresponding MGG and MG Data Input files were used to generate the MPS format matrix. The matrix generated for this case had 421 variables, only 66 constraints and sparsity factor of $17.99 \%$. The LP value (Lower Bound) obtained after PRIMAL agenda.was 11.50. Again hehighest resource level is 19 and the resource profile is as shown in Fig. 2.

\section{Model 3 : Reformulation of model 2.}

The precedence constraints of model 2 can be replaced by a set of inequalities:

$$
\sum_{k=1}^{t-p_{i}} y_{i k}-\sum_{k=1}^{t} y_{j k} \geq 0, \quad \forall(i, j) \in H, \quad \forall t
$$

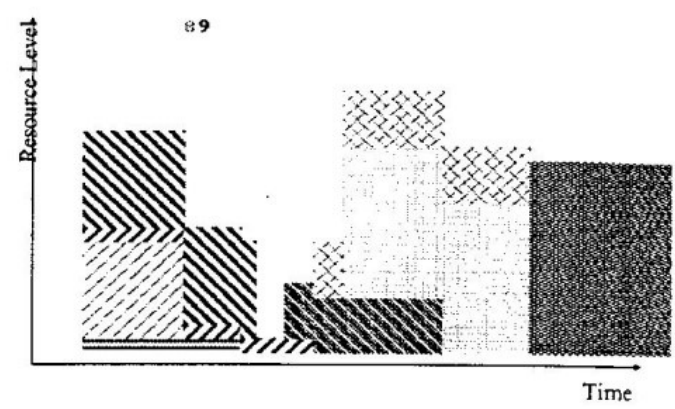

Fig. 2 : Resource profile representing the solution of model 2.

Although this set of inequalities contains more rows $\left(\mathrm{T}^{*}|\mathrm{H}|\right)$ than the previous formulation $(|\mathrm{H}|)$, it is totally unimodular ${ }^{[9]}$. We replace the precedence constraints in (11) by (12) to obtain model 3. $\min w$

s.t.

$\sum_{t} y_{i t}=1, \quad i=1, \ldots, n$

$\sum_{k=1}^{t-p_{i}} y_{i k}-\sum_{k=1}^{t} y_{j k} \geq 0 \quad \forall(i, j) \in H, \forall t$

$\sum_{i} r i\left(\sum_{k=t-p_{i}+1}^{t} y_{i k}\right) \leq w \quad t=1, \ldots, T$

$y \in\{0,1\}^{\mathrm{n}_{\mathrm{x}} \mathrm{T}}, \mathrm{w} \in 3_{\text {. }}$.

This model has the same number of variables as the previous case i.e. $\mathrm{nT}+1$, but more constraints $(\mathrm{T}(|\mathrm{H}|+1)+\mathrm{n})$. However. the number of constraints is still far less than the first model (which is $\mathrm{T}(2 \mathrm{n}+1)+\mathrm{n}+|\mathrm{H}|$ )

The model was tested on the same example. The size of the problem in terms of nonzeros was so large (23941) that the Matrix Generator (MG) could not generate the MPS format problem file. Instead, XPRESS-MP was used to generate the MPS matrix. The MPS problem was then solved by SCICONIC and the LP lower bound was 14.5, which is higher than the previous tested models. The optimal solution was obtained after only 615 iterations. The solution profile is as presented in 
Fig. 3.

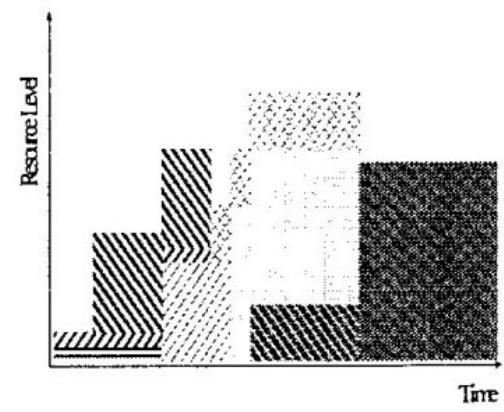

Fig. 3 : Resource profile representing the solution of model 3 .

\section{Model 4: Start-time and sequence determining variables}

Let $\mathrm{p}, \mathrm{w}, \mathrm{H}, \mathrm{T}$ be as defined in the previous models i.e. (6), (11) and (13). Let $x_{i}=$ Start time of activity $i{ }^{[10]}$. We observe that the interval $\left[x_{i}, x_{i}+1\right]$ for each $i$ is sufficient to define all the necessary high points of the resource profile. Fig. 4 illustrates this idea.

The height $h_{2} \in\left\{h_{1}, h_{2}, h_{3}, h_{4}, h_{5}\right\}$ is the highest peak that is intended to minimize.

If we sum the resource levels of all activities that falls into these intervals for each i (height at point i) we are guaranteed that the highest point will be one of these heights. The advantage of this model is that we only have to investigate $\mathrm{n}$ high points instead of all $\mathrm{T}$ points of the planning horizon.

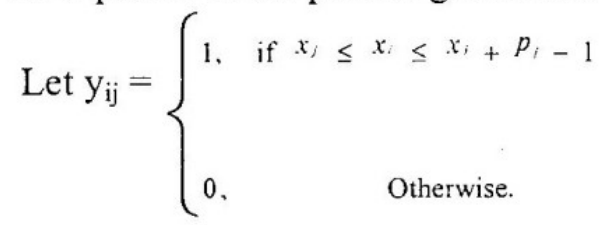

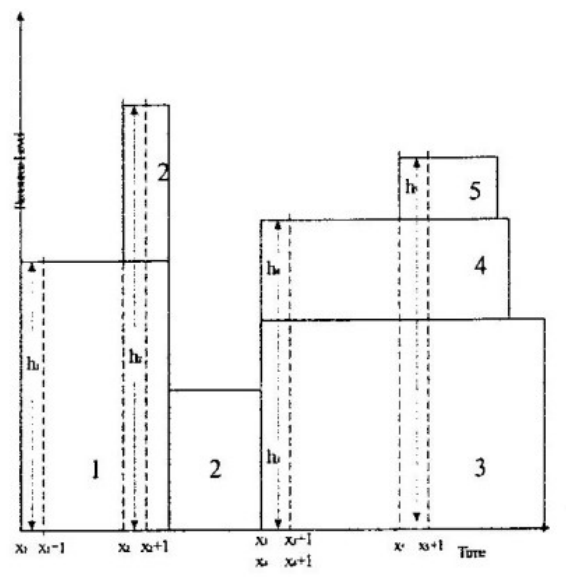

Fig. 4: An example showing the necessary highest points for a given set of five activities.

Then for each $i$, the height is given by $\sum_{j} r_{j}$ $y_{i j}$. We note that the number of binary variables in this case is $n^{2}$ instead of $n T$ as in the previous models.

The MIP model 4 is therefore;

Min w

s.t. (i) $\mathrm{x}_{\mathrm{j}}-\mathrm{x}_{\mathrm{i}} \geq \mathrm{p}_{\mathrm{i}} \quad \forall(\mathrm{i}, \mathrm{j}) \in \mathrm{H}$

(ii) $\sum_{\mathrm{j}} \mathrm{r}_{\mathrm{j}} \mathrm{y}_{\mathrm{ij}} \leq \mathrm{w} \quad \forall \mathrm{i}$

(iii) $\mathrm{y}_{\mathrm{ij}}$ reinforcement constraints. (14)

$y_{i j}$ reinforcements.

Define the condition

$x_{j} \leq x_{i} \leq x_{j}+p_{j}-1 \Rightarrow y_{i j}=1$ or $\left(x_{i}-x_{j} \geq 0\right)$

$\wedge\left(x_{j}+p_{j}-1-x_{i} \geq 0\right) \Rightarrow y_{i j}=1$.

Define two binary variables $u$ and $v$ such that;

$x_{i}-x_{j} \geq 0 \Rightarrow u_{i j}=1$, and

$\mathrm{x}_{\mathrm{j}}+\mathrm{p}_{\mathrm{j}}-1-\mathrm{x}_{\mathrm{i}} \geq 0 \Rightarrow \mathrm{v}_{\mathrm{ij}}=1$.

Then

$\left(\mathrm{x}_{\mathrm{i}}-\mathrm{x}_{\mathrm{j}} \geq 0\right) \wedge\left(\mathrm{x}_{\mathrm{j}}+\mathrm{p}_{\mathrm{j}}-1-\mathrm{x}_{\mathrm{i}} \geq 0\right) \Rightarrow \mathrm{y}_{\mathrm{ij}}=1$

$\equiv\left(u_{i j}+v_{i j}=2\right) \Rightarrow y_{i j}=1$

The constraint

$\left(\mathrm{x}_{\mathrm{i}}-\mathrm{x}_{\mathrm{j}}\right)+\varepsilon-\mathrm{Tu}_{\mathrm{ij}} \leq 0$ reinforces (15) where $\varepsilon$ is sufficiently small, say 1 .

Therefore $\mathrm{x}_{\mathrm{i}}-\mathrm{x}_{\mathrm{j}}-\mathrm{Tu}_{\mathrm{ij}} \leq-1$

The following inequality reinforces (16); $\left(\mathrm{x}_{\mathrm{j}}+\mathrm{p}_{\mathrm{j}}-1-\mathrm{x}_{\mathrm{i}}\right)+\varepsilon-\mathrm{Tv}_{\mathrm{ij}} \leq 0$ for $\mathrm{a}$ sufficiently small value of $\varepsilon$ say 1 . 
Therefore

$$
x_{j}-x_{i}-T v_{i j} \leq-p_{j}
$$

Similarly, (17) is defined as

$\left(u_{i j}+v_{i j}-2\right)+\varepsilon-y_{i j} \leq 0$

or $\quad u_{i j}+v_{i j}-y_{i j} \leq 1$

Applying (18), (19) and (20)in (14) we have model 4 as follows,

Min w

s.t.

(i) $x_{j}-x_{i} \geq p_{i}$
(ii) $\sum_{\mathrm{j}} \mathrm{r}_{\mathrm{j}} \mathrm{y}_{\mathrm{ij}} \leq \mathrm{w}$
(iii) $\mathrm{x}_{\mathrm{i}}-\mathrm{x}_{\mathrm{j}}-\mathrm{Tu}_{\mathrm{ij}} \leq-1$
$\forall 1$
(iv) $x_{j}-x_{i}-T v_{i j} \leq-p_{j}$
$\forall \mathrm{i}, \mathrm{j}$
(v) $u_{i j}+v_{i j}-y_{i j} \leq 1$
$\forall \mathrm{i}, \mathrm{j}$
$\forall \mathrm{i}, \mathrm{j}$

$\forall(\mathrm{i}, \mathrm{j}) \in \mathrm{H}$

$y, u, v \in\{0,1\}^{n_{x^{n}}}, w \in 3_{+}, x \in 9_{+}{ }^{n}$,

This model contains $3 n^{2}+n+1$ variables and $3 n^{2}+n+|H|$ constraints. Thus the problem matrix for our example is made up of 311 columns and 324 constraints with 997 non-zeros (sparsity of 0.99 ). The LP lower bound is found to be very poor (zero) and the optimal solution (19) is found after 6654 iterations. The corresponding resource is found on Figure 5.

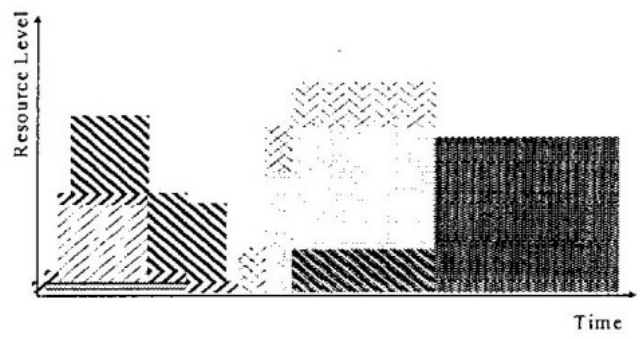

Fig. 5 : Resource profile corresponding to model 4.

The size of all four developed models are:

\begin{tabular}{|l|l|l|}
\hline & Rows & Columns \\
\hline Model 1 & $2 n(T+1)+T+|H|$ & $N(T+1)+1$ \\
\hline Model 2 & $n+T+|H|$ & $n T+1$ \\
\hline Model 3 & $n+T+T|H|$ & $n T+1$ \\
\hline Model 4 & $3 n^{2}+n+|H|$ & $3 n^{2}+n+1$ \\
\hline
\end{tabular}

The experimental results for the tested cases are presented in the summary of results. We define the deviation of the LP lower bound (LP) from the optimal integral solution (IP) as ;

$$
D e v=\frac{(I P-L P)}{I P} * 100
$$

The smaller the deviation the better is the lower bound. If $\mathrm{Dev}=0$, then IP $=$ LP. In this case the LP relaxation defines an integral polytope which gives the IP optimal solution just by solving the LP problem. The worst case is when Dev $=100$, which implies that $\mathrm{LP}=0$ which is the least lower bound.

Summary of Results

Problem: c302a; $\mathrm{n}=13 ; \mathrm{T}=29 ; \quad$ Optimal solution (IP) $=24$

\begin{tabular}{|l|l|l|l|l|}
\hline Model & 1 & 2 & 3 & 4 \\
\hline Rows & 827 & 60 & 236 & 538 \\
\hline Columns & 391 & 378 & 378 & 521 \\
\hline Non-zeros & 2281 & 3814 & 15197 & 1686 \\
\hline \%Sparsity & 0.71 & 16.82 & 7.50 & 0.60 \\
\hline LP Solutn & 18.14 & 14.64 & 18.79 & 0.00 \\
\hline Iterations(MIP) & 194667 & 2205 & 1266 & 72059 \\
\hline \%Dev. & 24.42 & 39.00 & 21.71 & 100.0 \\
\hline Time(sec.) & 24008 & 1665 & 44 & 24615 \\
\hline
\end{tabular}

Problem: $\mathrm{c} 302 \mathrm{~b} ; \mathrm{n}=10 ; \mathrm{T}=42 ;$ Optimal Solution (IP) $=19$

\begin{tabular}{|l|l|l|l|l|}
\hline Model & 1 & 2 & 3 & 4 \\
\hline Rows & 916 & 66 & 599 & 324 \\
\hline Columns & 431 & 421 & 421 & 311 \\
\hline Non-zeros & 2515 & 5000 & 23941 & 997 \\
\hline \%Sparsity & 0.64 & 17.99 & 9.49 & 0.99 \\
\hline LP Solutn & 13.02 & 11.50 & 14.50 & 0.00 \\
\hline Iterations(MIP) & 2778 & 4237 & 615 & 6654 \\
\hline \%Dev. & 31.47 & 39.47 & 23.68 & 100.0 \\
\hline Time(sec.) & 15855 & 611 & 67 & 3651 \\
\hline
\end{tabular}

Problem: $\mathrm{c} 204 \mathrm{~b} ; \mathrm{n}=12 ; \quad \mathrm{T}=43 ; \quad$ Optimal Solution (IP) $=31$

\begin{tabular}{|l|l|l|l|l|}
\hline Model & 1 & 2 & 3 & 4 \\
\hline Rows & 1117 & 73 & 787 & 462 \\
\hline Columns & 529 & 517 & 517 & 445 \\
\hline Non-zeros & 3100 & 6445 & 32724 & 1439 \\
\hline \%Sparsity & 0.52 & 17.08 & 8.04 & 0.70 \\
\hline LP Solutn & 18.19 & 15.03 & 18.68 & 0.00 \\
\hline Iterations(MIP) & 8266 & 3285 & 2306 & 1413 \\
\hline \%Dev. & 41.32 & 51.52 & 39.74 & 100.0 \\
\hline Time(sec.) & 3737.0 & 621.41 & 2935.9736552 .06 \\
\hline
\end{tabular}


Problem: c304a; $\mathrm{n}=13 ; \quad \mathrm{T}=40 ; \quad$ Optimal Solution (IP) $=33$

\begin{tabular}{|l|l|l|l|l|}
\hline Model & 1 & 2 & 3 & 4 \\
\hline Rows & 1125 & 72 & 774 & 539 \\
\hline Columns & 534 & 521 & 521 & 521 \\
\hline Non-zeros & 3130 & 6229 & 30081 & 1688 \\
\hline \%Sparsity & 0.52 & 16.61 & 7.46 & 0.60 \\
\hline LP Solutn & 20 & 15.67 & 21.90 & 0.00 \\
\hline Iterations(MIP) & 671 & 3237 & 1171 & 8841 \\
\hline \%Dev. & 39.39 & 52.52 & 33.64 & 100.0 \\
\hline Time(sec.) & 80064.83 & 481.64 & 80.82 & 75297.80 \\
\hline
\end{tabular}

Problem: c402a; $\mathrm{n}=13 ; \mathrm{T}=53 ; \quad$ Optimal Solution (IP) $=20$

\begin{tabular}{|l|l|l|l|l|}
\hline Model & 1 & 2 & 3 & 4 \\
\hline Rows & 1474 & 83 & 915 & 537 \\
\hline Columns & 703 & 690 & 690 & 512 \\
\hline Non-zeros & 4127 & 7244 & 46535 & 1684 \\
\hline \%Sparsity & 0.40 & 12.65 & 7.37 & 0.61 \\
\hline LP Solution & 14.81 & 14.37 & 19.5 & 0.00 \\
\hline Iterations(MIP) & 3269 & 5510 & 1893 & 13409 \\
\hline \%Dev. & 25.95 & 28.14 & 2.50 & 100.0 \\
\hline Time(sec.) & 6115.0 & 2032.86 & 713.0 & 72779.71 \\
\hline
\end{tabular}

Discussion

In all cases the least deviation from the optimal solution (IP) is given by model 3 . Due to its higher lower bound, model 3 takes fewer iterations and less time to find an IP optimal solution than the other cases (except problem c204b).

Problem c204b is an exception because the LP lower bound was too far from the optimal IP value (39.74\%). Although the lower bound (18.68) was better than in other models, the optimal value was 31 meaning that many iterations are required before reaching optimality. Each iteration takes more time due to the large size of the problem and hence more time is spent on the branch and bound procedure.

Conclusions

- Although model 3 has more non-zeros and therefore a larger MPS matrix than the other models, the LP lower bound was better in both cases. The optimal solution was obtained after fewer iterations than the other models (except for problem c204b).

- The only model, which did not involve the time-indexed variables, was model 4 , and the lower bounds obtained from this case were the worst. The timeindexed formulations are therefore better than start-time variable formulations.

\section{References}

1 Taha, H, "Operations Research. An Introduction", Macmillan Publishing Company, New York, Fifth Edition, 1992, pp. 457-461.

2 A. Mushi \& M. O’hEigeartaigh "A Simulated Annealing Procedure for the Resource Leveling Problem”. Dublin City University, School of Computer Applications. 1996, Working Paper: CA-0496.

3 Roger, G. S: "Operations Management, Decision Making in the operations function", McGraw Hill, Inc., New York, 1993.

4 SCICON Ltd : “MGG User Guide. Version 3.1”, London, 1991.

5 SCICON Ltd : "SCICONIC User Guide. Version 2.30”, London, 1993.

6 J. P. Sousa \& L. Wolsey, "A time-indexed formulation of non-preemptive single machine scheduling problems", Mathematical Programming, 54, (1992), pp353-367, North-Holland.

7 F. B. Talbot, "Resource-constrained project scheduling with time-resource tradeoffs: The nonpreemptive case", Management Science, 28, (1982), pp 1197-1210. 
8 Christofides et al, "Project Scheduling with Resource Constraints: A Branch and Bound approach". European Journal of Operations Research 29, (1987), pp. 262-273. North-Holland.

9 Williams, H. P.: "Model building in Mathematical Programming", John Wiley \& Sons, New York, 1985.

10 Marjan Akker, "LP-based solution methods for single-machine scheduling problems", $\mathrm{PhD}$. Thesis, Faculte des Sciences Appliquees, Universite Catholique de Louvain (Louvain-LaNeuve), 1989, Belgium. 